\title{
Behavior of fluorine and chlorine in volcanic ash of Sakurajima volcano, Japan in the sequence of its eruptive activity
}

\author{
Kenji Nogami ${ }^{1}$, Masato Iguchi $^{2}$, Kazuhiro Ishihara ${ }^{2}$, Jun-ichi Hirabayashi $^{1}$, and Daisuke Miki ${ }^{2}$ \\ ${ }^{1}$ Volcanic Fluid Research Center, Tokyo Institute of Technology, 641-36 Kusatsu, Agatsuma, Gunma 377-1711, Japan \\ ${ }^{2}$ Sakurajima Volcano Research Center, Disaster Prevention Research Institute, Kyoto University, \\ 1722-19 Yokoyama, Sakurajima, Kagoshima 891-1419, Japan
}

(Received November 12, 2004; Revised December 22, 2005; Accepted December 22, 2005; Online published May 12, 2006)

\begin{abstract}
At Sakurajima volcano, strombolian eruptions forerun vulcanian explosions, and volcanian explosions are often followed by continuous ash eruptions. Change in the mode of its eruptive activity is drastic and release of volatiles from magma corresponding to its eruptive activity is examined by determination of fluorine and chlorine in volcanic ash. The F contents of all the ash samples are markedly higher than the arithmetic mean value of Japanese volcanic rocks (ca. $300 \mu \mathrm{g} / \mathrm{g}$ ). Further, the water-soluble $\mathrm{Cl}$ contents of almost all the ash samples are also extremely higher than those of Japanese volcanic rocks (less than $50 \mu \mathrm{g} / \mathrm{g}$ ). This is attributed to fixation of $\mathrm{F}$ and $\mathrm{Cl}$ in hot gas onto the volcanic ash particles in the crater and/or eruption plumes. The differences in those contents among the "strombolian eruption"-, "vulcanian explosion"- and "continuous ash eruption" groups are significant, which implies that hot gas rich in $\mathrm{F}$ and $\mathrm{Cl}$ are issued during strombolian eruptions, while those halogens are less concentrated in hot gas after strombolian eruptions. The water-insoluble $\mathrm{Cl}$ content of the "strombolian eruption" group is significantly higher than those of the other groups. This result implies that $\mathrm{Cl}$ and the other volatiles are intensely released from magma during the doming period before vulcanian eruptions. Yet, it is inferred that continuous ash eruption is the final phase of vulcanian one.
\end{abstract}

Key words: fluorine, chlorine, strombolian eruption, vulcanian explosion, Sakurajima.

\section{Introduction}

Sakurajima is an andesitic stratovolcano and one of the most active volcanoes in the world. It lies about $5 \mathrm{~km}$ east of the city of Kagoshima at the southern end of Kyushu, Japan (Fig. 1). Recent eruptive phase has been sustained at the summit crater of the central cone, "Minamidake" since October 1955. Typical vulcanian explosions have occurred repeatedly, yet strombolian and continuous ash eruptions have been frequently observed. Strombolian eruptions forerun vulcanian explosions, and vulcanian explosions are often followed by continuous ash eruptions, which is the ordinary sequence of the eruptive activity of Sakurajima volcano.

Volcanic earthquakes observed at this volcano are classified as A-type, B-type, and explosion earthquakes. A-type earthquakes have clear P- and S-phases similar to ordinary tectonic earthquakes. While B-type earthquakes are microscale and characterized by the absence of clear S-phases. Explosion earthquakes are observed at the onset of vulcanian explosions. A-type earthquakes often precede swarms of B-type earthquakes, and the swarms are usually followed by explosive activity (Kamo, 1978). Spectrum analysis discloses that A-type earthquakes occur in brittle regions, whereas B-type earthquakes swarm in ductile or molten regions (Ishihara and Iguchi, 1989).

Geophysical observation revealed distribution of

Copyright (c) The Society of Geomagnetism and Earth, Planetary and Space Sciences (SGEPSS); The Seismological Society of Japan; The Volcanological Society of Japan; The Geodetic Society of Japan; The Japanese Society for Planetary Sciences; TERRAPUB hypocenters of volcanic earthquakes at this volcano (Kamo, 1978; Ishihara, 1990; Iguchi, 1994). Hypocenters of explosion earthquakes are concentrated inside a cylindrical chamber with a radius of $200 \mathrm{~m}$, at depths from 1 to $3 \mathrm{~km}$ beneath the summit crater. Those of B-type earthquakes are also concentrated inside the same chamber. Contrastively, tectonic-like A-type earthquakes occur around the chamber at depths from 1 to $4 \mathrm{~km}$ beneath the summit crater. Ishihara (1990) and Iguchi (1994) understood that the cylindrical chamber was a magma conduit, which connected the summit crater and a shallow magma reservoir, and that B-type and explosion earthquakes occurred at ductile regions inside the conduit, whereas A-type earthquakes occurred at brittle regions around the conduit.

Further, Ishihara and Iguchi (1989) subclassified B-type earthquakes into high $(\mathrm{BH})$, and low frequency (BL) types, and examined the relationship between seismic activity and ground deformation. Hypocenters of BH-type earthquakes are usually distributed in the region deeper than those of BL-type earthquakes. Yet, BH-type earthquake swarm is associated with slow inflation of the summit without significant eruptive activity, whereas BL-type earthquake swarms during rapid deflation of the summit with strombolian eruptions. They inferred that BH-type earthquake swarms were caused by magma intrusion into the conduit, whereas BLtype earthquakes were related to degassing from ascending magma. Dominant frequencies of BH-type, BL-type, and explosion earthquakes are different from each other although hypocenters of these earthquakes distribute inside 


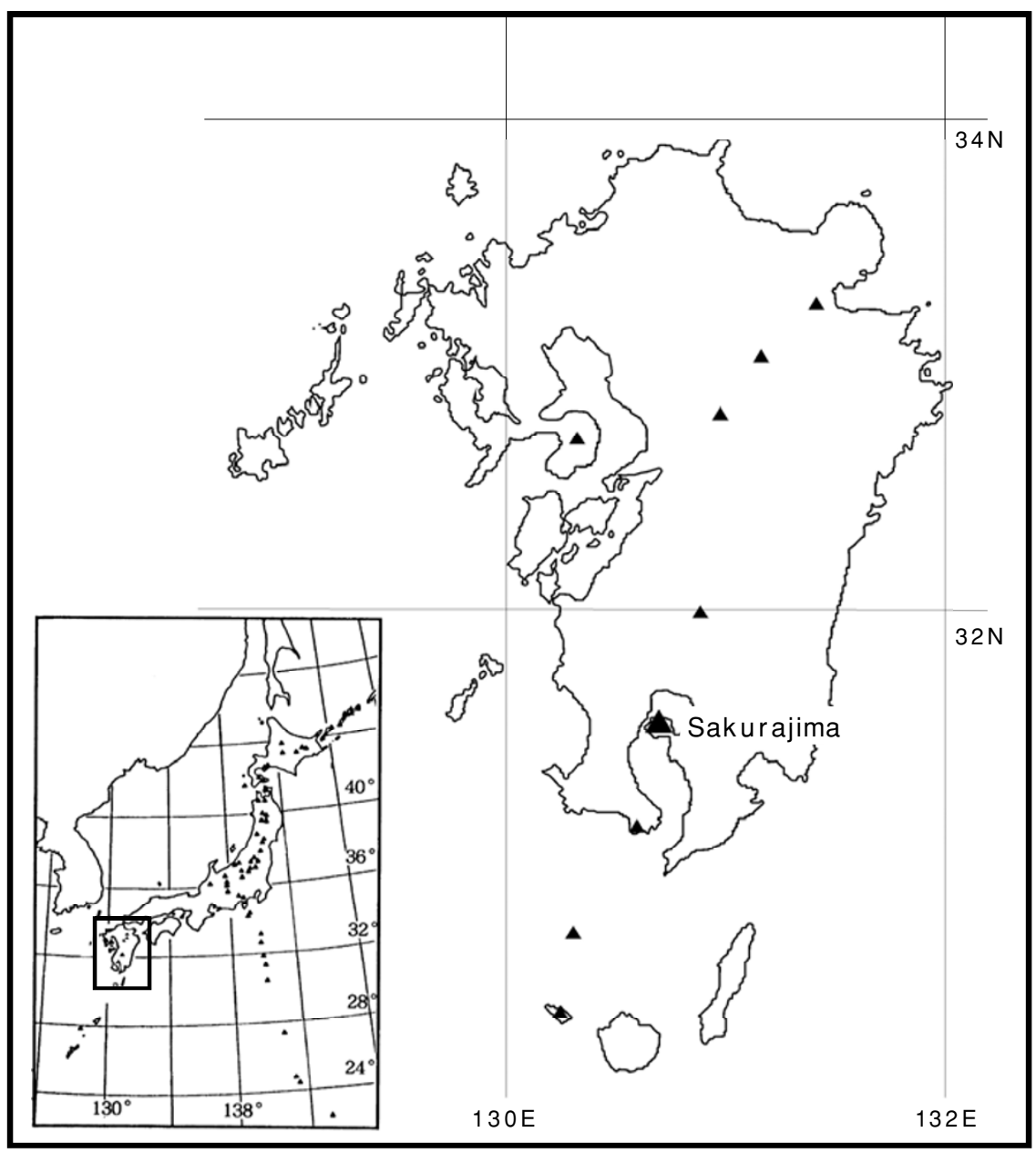

Fig. 1. Map showing location of Sakurajima volcano, southwest Kyushu, Japan.

the cylindrical chamber beneath the crater, which is attributed to difference in source processes affected by the state of the magma conduit including gas phase (Iguchi, 1994).

Magmatic volatiles are chemical substances dissolved in magma under pressure. Decompression of magma by moving toward Earth's surface causes exsolution of volatiles that become the driving force of explosive eruptions. Moreover, release of volatiles from magma changes its viscosity and density drastically, and these can influence violence of a volcanic eruption. Thus, examination of the behavior of volatiles will help us better understand eruptive activity of volcanoes.

Hydrogen fluoride (HF) and hydrogen chloride $(\mathrm{HCl})$ are major constituents of high temperature volcanic gases. Moreover, $\mathrm{F}$ and $\mathrm{Cl}$ are the second-most abundant volatile components after water in volcanic rocks. Yoshida (1963) heated powdered rocks in nitrogen gas flow at temperatures from $400^{\circ} \mathrm{C}$ to $1200^{\circ} \mathrm{C}$ to examine volatility of fluorine and chlorine compounds from silicates. This experiment showed that $\mathrm{F}$ was less volatile than $\mathrm{Cl}$. Yoshida $(1975,1990)$ performed further experiments for interaction between volcanic gases and rocks. These experiments revealed that $\mathrm{F}$ in gas phase was fixed onto rocks more easily than $\mathrm{Cl}$, and that $\mathrm{F}$ and $\mathrm{Cl}$ were fractionated through volcanic emanation. Hence, $\mathrm{F}$ and $\mathrm{Cl}$ contents of volcanic products could be good indicators of their behavior in volcanic processes. In this study, we determine $\mathrm{F}$ and $\mathrm{Cl}$ contents of volcanic ash issued by several types of eruptions of Sakurajima, and discuss release of volatiles from magma in the sequence of its eruptive activity.

\section{Samples}

The analyzed ash samples are the pristine products emitted by strombolian eruptions, vulcanian explosions and continuous ash eruptions from 1975 to 2002. These samples were collected at the foot of the volcano immediately after emission without contamination of soil and exposure to rain. All the ash samples are kept in plastic bags and cases. The ash samples of the strombolian eruptions are finer than $250 \mu \mathrm{m}$. While those of the other eruption types consist of particles finer than $250 \mu \mathrm{m}(70 \%)$ and those from $250 \mu \mathrm{m}$ to $500 \mu \mathrm{m}(30 \%)$.

\section{Analytical Procedure}

Fluorine and chlorine that are not exsolved from volcanic ash are tightly sealed within ash particles in water-insoluble forms. While $\mathrm{HF}$ and $\mathrm{HCl}$ in volcanic gas react with volcanic ash in an eruption plume, certain proportions of $\mathrm{F}$ and $\mathrm{Cl}$ are fixed onto the surfaces of the ash particles in watersoluble forms. Water-soluble $\mathrm{Cl}$ compounds are stabilized on the surface of the ash, whereas F compounds consider- 
Table 1(a). Contents (in $\mu \mathrm{g} / \mathrm{g}$ ) of $\mathrm{F}$ and $\mathrm{Cl}$ of the ash issued by strombolian eruptions.

\begin{tabular}{cccc}
\hline Date & F & s-Cl & ins-Cl \\
\hline $1975 / 3 / 12^{a)}$ & 1140 & 1840 & 350 \\
$1975 / 6 / 22$ & 790 & 1640 & 450 \\
$1985 / 4 / 13$ & 1050 & 1780 & 430 \\
$1985 / 7 / 29^{b)}$ & 890 & 2080 & 370 \\
\hline a.m. $^{1)}$ & 967.5 & 1835.0 & 400.0 \\
s.d. $^{2}$ & 157.14 & 183.58 & 47.61 \\
g.m. & & 1823.3 & 397.9 \\
\hline
\end{tabular}

a) water-soluble Na: $378 \mu \mathrm{g} / \mathrm{g}$ and water-soluble $\mathrm{K}: 96.3 \mu \mathrm{g} / \mathrm{g}$

${ }^{b)}$ water-soluble Na: $384 \mu \mathrm{g} / \mathrm{g}$ and water-soluble $\mathrm{K}: 85.8 \mu \mathrm{g} / \mathrm{g}$

1) Arithmetic mean

2) Standard deviation

${ }^{3)}$ Geometric mean

ably become water-insoluble with the lapse of time due to its high reactivity with silicates (e.g. Kamada, 1980). In the present case, the oldest samples were collected in the middle of 1970's, and F compounds on the ash particles are probably water-insoluble. Hence, total $\mathrm{F}$, water-soluble $\mathrm{Cl}$, and water-insoluble $\mathrm{Cl}$ contents are determined.

Fluorine is determined by the method of Tsuchiya et al. (1985). A powdered sample is weighed correctly and fused with $\mathrm{Na}_{2} \mathrm{O}_{2}$ in a nickel crucible. The cake is dissolved in pure water and the resulting suspension is centrifuged. Fluorine in the solution is distilled as trimethylfluorosilane and the fluoride concentration in the distillate is determined with an ion selective electrode.

Water-soluble chlorine is extracted by immersing a powdered sample overnight in pure water and the powder is centrifuged. Chloride in the solution is determined by mercuric thiocyanate-spectrophotomerty (Tomonari, 1962). Waterinsoluble $\mathrm{Cl}$ content is usually calculated as the difference between total $\mathrm{Cl}$ and water-soluble $\mathrm{Cl}$ content. In this case, water-soluble $\mathrm{Cl}$ contents of the ash samples are very high, which will be shown later. For the determination of waterinsoluble $\mathrm{Cl}$, powdered samples are pretreated for removal of water-soluble $\mathrm{Cl}$ by washing with pure water. Total $\mathrm{Cl}$ is determined by the method of Iwasaki et al. (1955) as improved by Ozawa (Yoshida et al., 1994; Oshima and Yoshida, 2005). A pretreated sample is weighed correctly and fused with $\mathrm{Na}_{2} \mathrm{CO}_{3}$ in a platinum crucible. The cake is dissolved in pure water and the resulting suspension is centrifuged. Chloride in the solution is determined by mercuric thiocyanate-spectrophotomerty. Water-soluble $\mathrm{Cl}$ contents of the pretreated samples are also determined and waterinsoluble $\mathrm{Cl}$ contents are calculated. The errors in the determination of both $\mathrm{F}$ and $\mathrm{Cl}$ are $\pm 10 \mu \mathrm{g} / \mathrm{g}$.

Sakurajima is a maritime volcano and sea salt contamination may increase water-soluble $\mathrm{Cl}$ contents of the ash samples. Thus, water-soluble $\mathrm{Na}$ and $\mathrm{K}$ of some ash samples having particularly high water-soluble $\mathrm{Cl}$ contents are also determined by atomic absorption spectrometry for examination of contamination of sea salt.
Table 1(b). Contents (in $\mu \mathrm{g} / \mathrm{g}$ ) of $\mathrm{F}$ and $\mathrm{Cl}$ of the ash issued by vulcanian explosions.

\begin{tabular}{|c|c|c|c|}
\hline Date & $\mathrm{F}$ & $\mathrm{s}-\mathrm{Cl}$ & ins- $\mathrm{Cl}$ \\
\hline $1975 / 3 / 19$ & 600 & 340 & 250 \\
\hline $1977 / 8 / 28$ & 670 & 1010 & 310 \\
\hline $1980 / 4 / 6$ & 470 & 60 & 230 \\
\hline $1980 / 5 / 5$ & 970 & 1130 & 250 \\
\hline $1980 / 7 / 18^{c)}$ & 1520 & 2800 & 260 \\
\hline $1981 / 11 / 22$ & 700 & 590 & 230 \\
\hline $1982 / 8 / 21$ & 480 & 750 & 230 \\
\hline $1983 / 5 / 22$ & 960 & 2120 & 320 \\
\hline $1983 / 6 / 22$ & 680 & 2140 & 290 \\
\hline $1983 / 8 / 22$ & 560 & 500 & 180 \\
\hline $1984 / 6 / 4$ & 810 & 1150 & 280 \\
\hline $1984 / 7 / 21^{d)}$ & 1270 & 2830 & 220 \\
\hline $1985 / 9 / 4$ & 390 & 200 & 200 \\
\hline $1999 / 12 / 10$ & 520 & 140 & 280 \\
\hline $2000 / 10 / 7$ & 1440 & 1930 & 300 \\
\hline $2002 / 11 / 13$ & 570 & 490 & 270 \\
\hline a.m. ${ }^{1)}$ & 788.1 & 1136.3 & 256.3 \\
\hline s.d. ${ }^{2)}$ & 351.27 & 937.72 & 39.81 \\
\hline g.m. ${ }^{3)}$ & 725.3 & 723.5 & 253.2 \\
\hline
\end{tabular}

c) water-soluble Na: $543 \mu \mathrm{g} / \mathrm{g}$ and water-soluble $\mathrm{K}: 153 \mu \mathrm{g} / \mathrm{g}$ ${ }^{d)}$ water-soluble Na: $1010 \mu \mathrm{g} / \mathrm{g}$ and water-soluble K: $269 \mu \mathrm{g} / \mathrm{g}$ ${ }^{1)}{ }^{-3)}$ Same as in Table 1(a)

Table 1(c). Contents (in $\mu \mathrm{g} / \mathrm{g}$ ) of $\mathrm{F}$ and $\mathrm{Cl}$ of the ash issued by continuous ash eruptions.

\begin{tabular}{|c|c|c|c|}
\hline Date & $\mathrm{F}$ & $\mathrm{s}-\mathrm{Cl}$ & ins- $\mathrm{Cl}$ \\
\hline $1982 / 7 / 25$ & 650 & 880 & 230 \\
\hline $1982 / 7 / 29$ & 670 & 910 & 240 \\
\hline $1983 / 7 / 13$ & 720 & 810 & 260 \\
\hline $1983 / 7 / 29$ & 590 & 1060 & 220 \\
\hline a.m. ${ }^{1)}$ & 657.5 & 915.0 & 237.5 \\
\hline s.d. ${ }^{2)}$ & 53.77 & 105.36 & 17.08 \\
\hline g.m. ${ }^{3)}$ & 655.8 & 910.6 & 237.0 \\
\hline
\end{tabular}

1)-3) Same as in Table 1(a)

\section{Results}

Analytical results and statistical parameters are listed in Table 1(a)-1(c) according to the mode of eruption. Watersoluble $\mathrm{Na}$ and $\mathrm{K}$ contents of the selected samples are footnoted in Table 1(a) and 1(b). Their weight ratios of $\mathrm{Na}$ to $\mathrm{K}$ range from 3.54 to 4.48 , and they are much lower than that of seawater (ca. 27.5). This shows that all the ash samples are probably free from sea salt contamination.

Halogen contents of volcanic rocks in Japan have approximately lognormal distributions (Iwasaki et al., 1957; Yoshida et al., 1971). It is appropriate to take logarithmic values for applying statistical analysis to the data for the halogen contents. However, some samples of the "vul- 
canian explosion" group have low water-soluble $\mathrm{Cl}$ contents and the deviations from the other values are exaggerated when we take logarithms of those values. The differences between the arithmetic mean values and corresponding geometric mean values are very small except for watersoluble $\mathrm{Cl}$ in the "vulcanian explosion" group as shown in Table 1(a)-1(c). Hence, we can use the normal distribution approximation for the following discussion.

\section{Discussion}

5.1 Differences in $\mathrm{F}$ and water-soluble $\mathrm{Cl}$ contents among the three types of eruption

The arithmetic mean values of $\mathrm{F}$ and water-soluble $\mathrm{Cl}$ contents of Japanese volcanic rocks are ca. $300 \mu \mathrm{g} / \mathrm{g}$ (Yoshida and Tsuchiya, 2004), and less than $50 \mu \mathrm{g} / \mathrm{g}$ (Iwasaki et al., 1957; Yoshida et al., 1971), respectively. The $\mathrm{F}$ and water-soluble $\mathrm{Cl}$ contents of all the ash samples shown in Table 1(a)-1(c) are extremely higher than these values. Kamada $(1957,1980)$ found that the volcanic ash issued by the 1955 eruption of Sakurajima had considerably high $\mathrm{F}$ and $\mathrm{Cl}$ contents, and that $\mathrm{F}$ and $\mathrm{Cl}$ compounds were considerably fixed on the ash in water-soluble forms. He inferred that fixation of $\mathrm{F}$ and $\mathrm{Cl}$ in hot gas onto the ash particles, within the crater and/or eruption columns, increased those contents of the ash markedly. Moreover, Yoshida et al. (1968) exposed powdered rocks to fumarolic gases containing $\mathrm{HF}$ and $\mathrm{HCl}$ in a certain period. They evidenced that $\mathrm{F}$ and $\mathrm{Cl}$ contents of the employed rocks highly increased, and that $\mathrm{F}$ was mainly stabilized in water-insoluble form. Whereas $\mathrm{Cl}$ was mostly fixed in water-soluble form. Thus, the present ash samples are highly enriched in $\mathrm{F}$ and watersoluble $\mathrm{Cl}$, which is probably attributed to fixation of volcanic gases onto the ash particles.

The $\mathrm{F}$ and water-soluble $\mathrm{Cl}$ contents of the "strombolian eruption"-, "vulcanian explosion"-, and "continuous ash eruption" groups are different from one another (Fig. 2). This may suggest change in $\mathrm{F}$ and $\mathrm{Cl}$ concentrations in hot gas in the sequence of the eruptive activity. Those contents of the "vulcanian explosion" group range widely, however, Dixon's Q-test for outliers (Dixon, 1953) shows that all the samples of this group belong to the same normal distribution at the $1 \%$ significance level. The significance of dissimilarity in the arithmetic mean values among the three groups is examined by t-test (Table 2). Yet, differences in the variances among them are also examined by F-test (Table 3 ).

The arithmetic mean values of the $\mathrm{F}$ and water-soluble $\mathrm{Cl}$ contents of the "strombolian eruption" group are significantly higher than those values of the other groups. While those values of the "continuous ash eruption" group do not differ from those of the "vulcanian explosion" group at the $5 \%$ significance level. These results support the deduction from Fig. 2 that $\mathrm{F}$ and water-soluble $\mathrm{Cl}$ contents of the volcanic ash depend on the mode of the eruption. They imply transition of $\mathrm{F}$ and $\mathrm{Cl}$ concentrations in hot gas issued from magma in the sequence of the eruptive activity. Hot gas enriched in $\mathrm{F}$ and $\mathrm{Cl}$ was issued from magma during strombolian eruptions, while it was depleted in the halogens after this stage. Fluorine and chlorine concentrations in hot gas did not change significantly between vulcanian
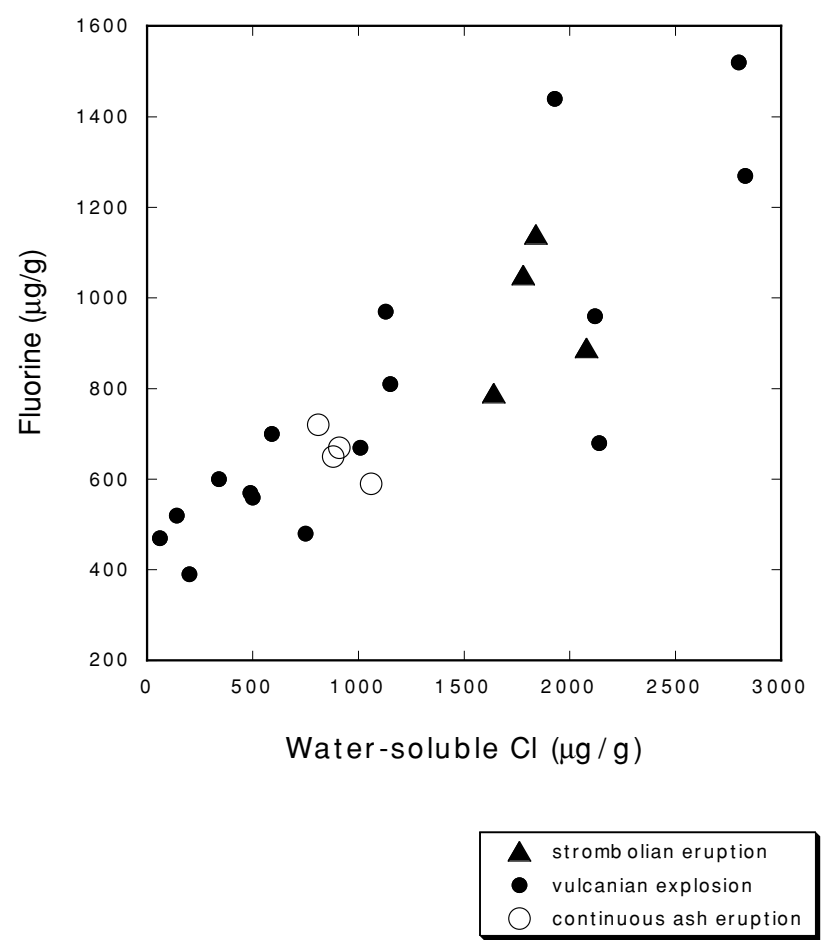

Fig. 2. Variation of $\mathrm{F}$ and water-soluble $\mathrm{Cl}$ contents of the ash samples issued by strombolian eruption, vulcanian explosion and continuous ash eruption.

eruption stage and continuous eruption stage.

\subsection{Difference in water-insoluble $\mathrm{Cl}$ contents among the three types of eruptions}

Figure 3 shows range of the water-insoluble $\mathrm{Cl}$ contents of the three groups. The water-insoluble $\mathrm{Cl}$ contents of the "strombolian eruption" group are higher than those of the other groups. While that of the "continuous ash eruption" group is within the range of that of the "vulcanian explosion" group. Significance of dissimilarity in the arithmetic mean value among the three groups is examined by t-test (Table 2). Difference in the variance among them is also examined by F-test (Table 3 ).

The arithmetic mean value of the water-insoluble $\mathrm{Cl}$ content of the "strombolian eruption" group is higher than those values of the others at $1 \%$ significance level. While the difference in the value between the "vulcanian explosion"- and "continuous ash eruption" groups is not recognizable at the $5 \%$ level. These statistic examinations support the deduction from Fig. 3 as shown above. The difference in the value among the three groups indicates that degassing of $\mathrm{Cl}$ is intensive before vulcanian explosion, while it is less intensive after this stage.

One might attempt to explain the difference in the waterinsoluble $\mathrm{Cl}$ contents among the three groups as indicating state of the magma conduit in the sequence of the volcanic activity (Fig. 4). During strombolian eruption, the conduit is filled with fluid magma. Volatiles that are non-explosively exsolved from magma rise upward in the magma conduit. Therefore, the upper part of the magma column has high volatile contents (Fig. 4(a)). Formation of a lava dome at the crater bottom is frequently observed before vulcanian explosions. Chlorine and the other volatiles 
Table 2. Differences in the arithmetic mean values among the groups examined by t-test.

\begin{tabular}{l} 
Fluorine \\
strombolian eruption $\gg$, vulcanian explosion $\sim$ continuous ash eruption \\
\hline Water-soluble Chlorine \\
strombolian eruption $>$ vulcanian explosion $\sim$ continuous ash eruption \\
strombolian eruption $\gg$, continuous ash eruption \\
\hline Water-insoluble Chlorine \\
strombolian eruption $\gg$, vulcanian explosion $\sim$ continuous ash eruption \\
\hline , and $>$ mean that the difference is significant at the $1 \%$ level and the $5 \%$ level, respectively. \\
$\sim$ means the difference is not significant at the $5 \%$ level.
\end{tabular}

Table 3. Differences in the variances among the groups examined by F-test.

\begin{tabular}{l} 
Fluorine \\
vulcanian explosion $\sim$ strombolian eruption $\sim$ continuous ash eruption \\
vulcanian explosion $\gg$, continuous ash eruption \\
\hline Water-soluble Chlorine \\
vulcanian explosion $>$ strombolian eruption $\sim$ continuous ash eruption \\
vulcanian explosion $\gg$, continuous ash eruption \\
Water-insoluble Chlorine \\
vulcanian explosion $\sim$ strombolian eruption $\sim$ continuous ash eruption \\
》, and $>$ mean that the difference is significant at the $1 \%$ level and the $5 \%$ level, respectively. \\
$\sim$ means the difference is not significant at the $5 \%$ level.
\end{tabular}

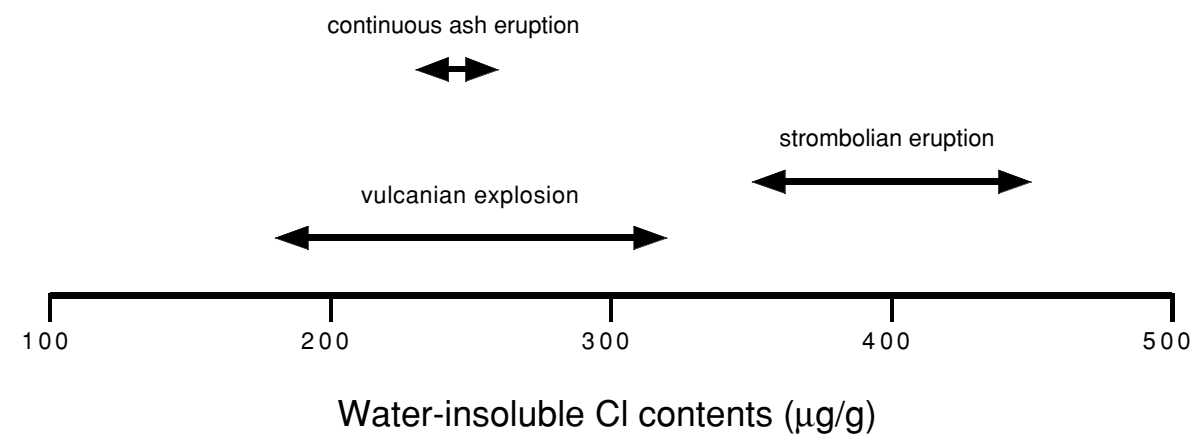

Fig. 3. Range of water-insoluble $\mathrm{Cl}$ contents of the ash samples issued by strombolian eruption, vulcanian explosion and continuous ash eruption.

are intensely exsolved from magma during the doming period and they are chambered beneath a lava dome. Release of volatiles from magma increases its viscosity, which furthers dome formation there (Fig. 4(b)). Then, vulcanian explosions eject pyroclastics of degassed magma (Fig. 4(c)). The difference in volatile contents of pyroclastics between vulcanian explosions and continuous ash eruptions is not recognizable, which suggests that continuous ash eruption is the final phase of vulcanian explosion. Ishihara (1985) deduced from geophysical observation that a lava dome plugged the magma conduit and hot gas was trapped in gas pockets beneath the dome, and that this stage might correspond to decrease of smoke before vulcanian explosions. Further, Iguchi (1994) implied that the conduit was filled with fluid magma during BL-type earthquakes, whereas the conduit was filled with a mixture of viscous magma and gases after BL-type earthquakes.

\section{Conclusions}

Determination of $\mathrm{F}$ and $\mathrm{Cl}$ contents of the ash issued from Sakurajima volcano by strombolian eruption, vulcanian explosion, and continuous ash eruption leads to the following conclusions.

The $\mathrm{F}$ and water-soluble $\mathrm{Cl}$ contents of the ash samples are extremely higher than those of Japanese volcanic rocks, which can be attributed to fixation of $\mathrm{F}$ and $\mathrm{Cl}$ in hot gas onto the ash particles. The sequence of the eruptive activity from strombolian eruption to vulcanian explosions, and then to continuous ash eruptions are closely related to release of volatiles from magma. During strombolian eruptions, volatile-rich fluid magma fills the conduit. Volatiles that are non-explosively exsolved from magma rise upward in the magma conduit. Then, $\mathrm{F}, \mathrm{Cl}$ and probably other volatile components are concentrated in hot gas issued from magma in this stage. Volatiles are intensely released from 


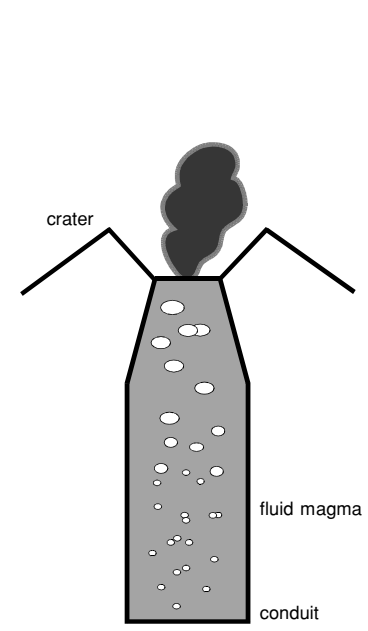

a) strombolian eruption

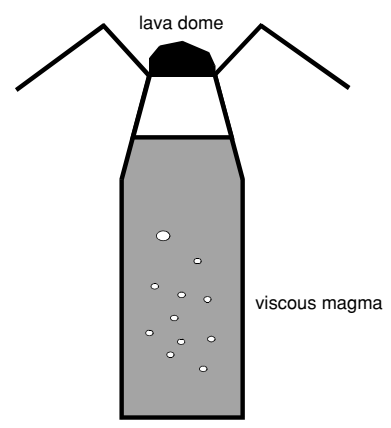

b) doming period before explosion

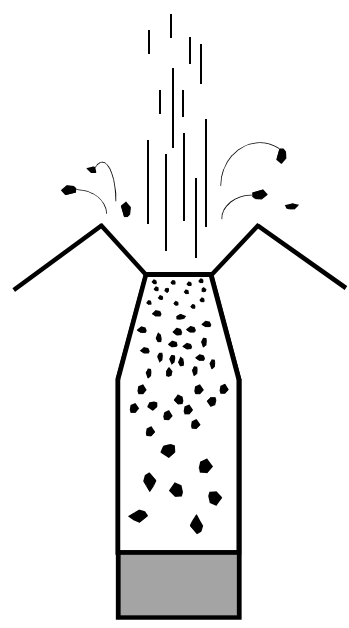

c) vulcanian explosion c) vulcanian explosion
$\sim$ continuous ash eruption

Fig. 4. Inferred state of the magma conduit including gas phase during strombolian eruption (a), doming period before vulcanian explosion (b) and vulcanian explosion to continuous ash eruption (c).

magma during doming periods before vulcanian explosions, and they are chambered beneath lava domes to become the driving force of vulcanian explosion. At the onset of vulcanian explosions, pyroclastics of degassed magma are ejected, and hot gas is depleted in $\mathrm{F}$ and $\mathrm{Cl}$ after this stage. After vulcanian eruption, the change in $\mathrm{F}$ and $\mathrm{Cl}$ concentrations in hot gas is not significant. And pyroclastics of continuous ash eruptions are less different from those of vulcanian explosions in volatile contents, which suggests that continuous ash eruption is the final phase of vulcanian explosions.

Acknowledgments. We would like to express our hearty thanks to the staff members of Sakurajima Volcano Research Centre, Disaster Prevention Research Institute, Kyoto University for providing us many samples and information on volcanic activity. We are also grateful to Dr. Minoru Yoshida for constructive suggestion to improve this manuscript. This study was supported by Grant in Aid from the Disaster Prevention Research Institute, Kyoto University.

\section{References}

Dixon, W. J., Processing data for outliers, Biometrics, 9, 74-89, 1953.

Iguchi, M., A vertical expansion source model for the mechanism of earthquakes originated in the magma conduit of an andesitic volcano: Sakurajima, Japan, Bull. Volcanol. Soc. Japan, 39, 49-67, 1994.

Ishihara, K., Dynamical analysis of volcanic explosion, J. Geodynamics, 3, 327-349, 1985.

Ishihara, K., Pressure sources and induced ground deformation associated with explosive eruptions at an andesitic volcano, Sakurajima Volcano, Japan, in Magma Transport and Storage, edited by M. P. Ryan, 335 pp., John Wiley and Sons, Chichester, 1990.

Ishihara, K. and M. Iguchi, The relationship between micro-earthquake swarms and volcanic activity at Sakurajima Volcano, Ann. Rep. Disas. Prev. Res. Inst. Kyoto Univ., 32B-1, 1-11, 1989 (in Japanese).

Iwasaki, I., T. Katsura, and N. Sakato, Geochemical investigation of the volcanoes In Japan 31, Method for the determination of chlorine in the volcanic rocks, Nippon Kagaku Zasshi, 76, 1116-1119, 1955 (in Japanese).

Iwasaki, I., T. Katsura, N. Sakato, and M. Hirayama, Geochemical investigation of the volcanoes in Japan 41, Chlorine in the volcanic rocks, Nippon Kagaku Zasshi, 78, 164-172, 1957 (in Japanese).

Kamada, M., Some subjects on halogen in volcanic products, Paper pre- sented at Annual Meeting of Volcanol. Soc. Japan, Izu-Oshima, Japan, 93-94, 1957 (in Japanese).

Kamada, M., Peculiarity of volcanic activity of Sakurajima viewed from chemistry, Report of Sakurajima Area Investigation Committee, Kagoshima, Prefectural Government, Kagoshima, 29-40, 1980 (in Japanese).

Kamo, K., Some phenomena before the summit eruptions at Sakura-zima Volcano, Bull. Volcanol. Soc. Japan, 23, 53-64, 1978 (in Japanese with English abstract).

Oshima, M. and M. Yoshida, Determination of Fluorine and Chlorine in GSJ Reference Samples "Igneous Rock Series", Bull. Volcanol. Soc. Japan, 2005 (in Japanese with English abstract), in press.

Tomonari, A., Improvement of the method for the photometric determination of micro amounts of chloride, Nippon Kagaku Kaishi, 83, 693-695, 1962 (in Japanese).

Tsuchiya, K., T. Imagawa, K. Yamaya, and M. Yoshida, Separation of micro Amounts of fluoride coexisting with large amounts of aluminium and silica by improved trimethylsilylating distillation, Anal. Chim. Acta, 176, 151-159, 1985.

Yoshida, M., The volatilization of chlorine and fluorine compounds from igneous rocks on heating, Bull. Chem. Soc. Japan, 36, 773-782, 1963.

Yoshida, M., An experimental study for the fractionation of fluorine and chlorine in volcanic gases through the reaction of them with volcanic rocks, Nippon Kagaku Kaishi, 1975, 449-454, 1975 (in Japanese with English abstract).

Yoshida, M., Fractionation of fluorine and chlorine through the volcanic process, in Geochemistry of Gaseous Elements and Compounds, edited by E. M. Durrance, E. M. Galimov, M. E. Hinkle, G. M. Reimer, R. Sugisaki, and S. S. Augustithis, 163 pp., Theophrastus Publications, S.A., Athens, 1990.

Yoshida, M. and K. Tsuchiya, Fluorine and chlorine contents in the products of the 1783 (Temmei) eruption of Asama volcano, Bull. Volcanol. Soc. Japan, 49, 65-72, 2004.

Yoshida, M., T. Ozawa, and J. Ossaka, Addition of fluorine and chlorine to volcanic rocks accompanied with their alteration by active fumarolic gases, Nippon Kagaku Zasshi, 89, 930-933, 1968 (in Japanese with English abstract).

Yoshida, M., K. Takahashi, N. Yonehara, T. Ozawa, and I. Iwasaki, The fluorine, chlorine, bromine and iodine contents of volcanic rocks in Japan, Bull. Chem. Soc. Japan, 44, 1844-1850, 1971.

Yoshida, M., K. Uchikawa, and J. Hirabayashi, Fluorine and chlorine contents in the lavas and ejecta of the 1986 eruption of Izu-Oshima volcano, J. Volcanol. Geotherm. Res., 63, 231-241, 1994.

K. Nogami (e-mail: knogami@ksvo.titech.ac.jp), M. Iguchi, K. Ishihara, J. Hirabayashi, and D. Miki 